\title{
NUEVOS ESTUDIOS SOBRE LAS LUCHAS INDÍGENAS EN ARGENTINA: DERECHOS, TIERRAS E IDENTIDADES EN DISPUTA
}

HORACIO MIGUEL HERNÁN ZAPATA ${ }^{1}$

UNR/CONICET

\section{RESENHA}

GORDILLO, Gastón; HIRSCH, Silvia (Orgs.). Movilizaciones indígenas e identidades en disputa en la Argentina. Buenos Aires: La Crujía Ediciones, 2010. 288 p.

Los últimos lustros del siglo XX y los inicios del XXI han mostrado la revitalización de las luchas de los pueblos indígenas en América Latina, un movimiento por la reafirmación de sus derechos, tierras e identidades que ha trascendido el ámbito de la política para internarse en el terreno de las ciencias sociales y, desde este lugar, actualizar la agenda de enfoques, problemáticas y análisis de los investigadores. En el cruce de diversas matrices conceptuales, teóricas y metodológicas se encuentra el libro Movilizaciones indígenas e identidades en disputa en la Argentina, compilado por Mónica Gordillo y Silvia Hirsch. El volumen examina los diversos costados (históricos, culturales y políticos) de los campos de disputa que han conformado la trayectoria de los pueblos

\footnotetext{
${ }^{1}$ Profesor y Licenciado en Historia por la Facultad de Humanidades y Artes de la Universidad Nacional de Rosario (UNR). Becario doctoral del Consejo Nacional de Investigaciones Científicas y Técnicas (CONICET) y docente-investigador de la Universidad Nacional de Rosario (UNR). E-mail: horazapatajotinsky@hotmail.com.
}

Espaço Ameríndio, Porto Alegre, v. 7, n. 1, p. 366-371, jan./jun. 2013. 
HORACIO MIGUEL HERNÁN ZAPATA - Nuevos estudios sobre las luchas indígenas...

originarios en la Argentina. A partir de un conjunto de artículos centrados en estudios de caso que exploran una significativa porción de la geografía del país y que han sido elaborados por algunos de los más reconocidos referentes de la antropología argentina, el texto presenta al futuro lector un bosquejo histórico y etnográfico de la gran diversidad de experiencias, identidades, prácticas y aspiraciones de las comunidades aborígenes que desde coyunturas recientes han cuestionado -y contribuido a erosionar- el otrora mito fundacional de Argentina como una Nación "homogénea" y con una población de origen "blanco y europeo" y "llegada de los barcos".

Con el objeto de presentar los procesos históricos, sociales y políticos que forman el trasfondo de todas las contribuciones, el capítulo introductorio de Gordillo y Hirsch analiza la historia de las narrativas hegemónicas, políticas estatales y movilizaciones que han forjado "la cuestión indígena" en la Argentina. El artículo estudia cómo durante la mayor parte del siglo XX los grupos indígenas constituyeron, en la tesis de los autores, una suerte de "presencia ausente" en los imaginarios nacionales, donde su invisibilización fue paralela a los intentos estatales por lidiar con su ineludible gravitación en varias regiones del país. Además, el trabajo examina cómo este proceso comenzó a ser subvertido en la década de 1990 con la emergencia de nuevas formas de activismo que, además de centrarse en demandas de corte local, le han dado una nueva presencia pública al componente indígena, contribuyendo así a redefinir los significados de la nacionalidad argentina.

Si bien los restantes nueve artículos de la compilación no se encuentran reunidos en apartados, es posible trazar ciertos bloques temáticos. El primero, integrado por tres capítulos, enfoca sendas investigaciones sobre la lucha por la titularidad de la tierra y el reconocimiento político, problemática que encapsula buena parte de los conflictos actuales entre grupos indígenas y el Estado. Así, el artículo de Claudia Briones y Ana Ramos propone replantear la mirada teórica de los estudios sobre movilizaciones indígenas, que suelen centrarse en momentos de alta conflictividad y visibilidad pública y, por ende, dejan de lado hiatos, pausas y reposicionamientos de larga duración que son menos visibles pero no menos importantes en la constitución de 
HORACIO MIGUEL HERNÁN ZAPATA - Nuevos estudios sobre las luchas indígenas...

acciones políticas. Las autoras centran su estudio en el activismo mapuche-tehuelche en Chubut para sacar a la luz estas articulaciones políticas y subjetivas a varios niveles: experiencias y afectos personales, diferencias generacionales, luchas familiares y comunitarias por la tierra, prácticas de organización política así como intervenciones estatales. Por su parte, Gastón Gordillo realiza un análisis comparativo de las demandas guaraníes por la posesión de la tierra en la zona azucarera de las provincias de Salta y Jujuy, en el actual noroeste argentino, contraponiendo el reclamo en la localidad de Hipólito Yrigoyen (Salta) contra el ingenio San Martín del tabacal por el lugar conocido como "La Loma" con la movilización por la propiedad de tierras fiscales cerca del pueblo de Vinalito (Jujuy). Gordillo examina ambas luchas como procesos de reterritorialización, por los cuales actores guaraníes urbanos han buscado desplazarse a lugares rurales y con ello contrarrestar experiencias de desarraigo territorial así como la acusación desde sectores de poder de que ellos no serían "indígenas argentinos" sino "indígenas bolivianos" sin derecho a la tierra. El autor analiza estas luchas guaraníes por espacios rurales en su entrelazamiento con disputas sobre nacionalidad, experiencias de alienación urbana y memorias sobre el pasado agrario de sus ancestros. El trabajo de Ana María Spadafora, Mariana Gómez y Marina Matarrese realiza un contrapunto entre el caso de los pilagá y los tobas del oeste de la provincia de Formosa para analizar la relación entre formas de organización política y programa de entrega de tierras. Por un lado, consideran las dificultades que surgen cuando comunidades indígenas son sometidas a procedimientos burocráticos basados en criterios legales ajenos a ellas, sobre todo en relación a la distribución de tierras por parte del Estado. Por otro lado, su trabajo muestra que mientras los tobas del oeste de Formosa lograron constituir una organización política unificada con una relativamente importante capacidad de negociación, articulada en base a una red de contactos y relaciones con ONGs, los intentos de crear una organización similar por parte de los dirigentes pilagá ha enfrentado importantes obstáculos y resistencias internas originadas en el seno de sus propias comunidades, en parte debido a su mayor dispersión espacial y a relaciones clientelares creadas por el gobierno provincial. 
HORACIO MIGUEL HERNÁN ZAPATA - Nuevos estudios sobre las luchas indígenas...

El segundo bloque se centra en las dimensiones culturales y lingüísticas de las nuevas formas de emergencia indígena, mostrando cómo la lengua se trasforma en un espacio político que incluye tensiones en el proceso de su enseñanza y en el establecimiento de consenso sobre los grafemas a ser usados para escribirla. En este sentido, el trabajo de Florencia Ciccone y Silvia Hirsch analiza de qué manera las relaciones trasnacionales de los tapietes de Salta con grupos tapietes en Bolivia y Paraguay han conducido a una revalorización de sus prácticas culturales y lingüísticas y otorgado una mayor visibilidad a una etnia que se encuentra en un contexto urbano (la ciudad de Tartagal) y en una situación de fuertes presiones sociales, económicas y culturales. A su turno, el artículo de Axel Lazzari examina la implementación de un "taller de lengua y cultura rankülche" para reflexionar sobre el lugar que ha ocupado la lengua en las estrategias de reconocimiento y emergencia del activismo rankülche en la provincia de La Pampa. El autor analiza, en primer lugar, los múltiples significados y motivaciones asociados a la recuperación de la lengua por parte de dirigentes rankülche, lingüístas, antropólogos, funcionarios gubernamentales y asistentes no-indígenas de los talleres. Además, Lazzari muestra cómo estos talleres han oscilado en crear representaciones fetichizadas de la lengua rankülche como conjunto de "palabras sueltas"- y constituirse como espacio político por el cual el movimiento rankülche ha buscado ganar visibilidad pública en la provincia.

El tercer bloque, formado por los últimos cuatro capítulos, abordan otras facetas políticas, identitarias y corporales de las luchas de los pueblos originarios, algunas de ellas íntimamente ligadas o no a organizaciones o movimientos políticos, pero que han sido igualmente parte de campos de poder y disputa. El trabajo de Diego Escolar analiza los conflictos y formas de dominación que existen en el interior de los movimientos indígenas en la Argentina, centrándose en las "once comunidades huarpes" de Guanacache, en la provincia de Mendoza. El autor muestra que a pesar de la narrativa de la "extinción de los huarpes", en esta región muchos pobladores rurales nunca perdieron prácticas, identificaciones y memorias de corte indígena. Pero estas formas locales de subjetividad huarpe fueron institucionalizadas $y$ transformadas en la década de 1990 por la influencia de activistas

Espaço Ameríndio, Porto Alegre, v. 7, n. 1, p. 366-371, jan./jun. 2013. 
HORACIO MIGUEL HERNÁN ZAPATA - Nuevos estudios sobre las luchas indígenas...

huarpes urbanos, por las nuevas políticas estatales y, sobre todo, por el accionar de actores no-indígenas, como un sacerdote católico y directores de escuelas. El autor examina las relaciones de poder por las cuales estos últimos se consolidaron como "representantes" de las comunidades de Guanacache así como las resistencias y debates que dicha apropiación ha generado entre pobladores huarpes.

El artículo de Ana Vivaldi analiza cómo personas tobas que viven en un barrio periurbano de la ciudad de Formosa hacen uso de zonas de montes en tierras privadas circundantes, los significados que ellos asocian a dichos lugares y los conflictos que sus prácticas han creado con agentes del Estado, particulares y empleados de estancias. Atraídos a la ciudad por la aspiración de "progresar", y al mismo tiempo confinados por el Estado a un barrio estigmatizado como "aborigen", hombres y mujeres tobas organizan partidas de cacería o de recolección de totoras al monte no sólo por motivos económicos o siguiendo una "tradición cultural". Como muestra Vivaldi, estas prácticas también son parte de un proyecto alternativo del uso del espacio que busca limitar formas de disciplinamiento y control territorial.

En su trabajo, Gabriela Karasik analiza la estrecha relación existente entre corporalidad, indumentaria y marcadores étnicos en las tierras altas de Jujuy. La autora comienza examinando los distintos modos en que desde la colonia hasta fines del siglo XX, ciertos tipos de ropa y arreglos del pelo fueron utilizados para marcar la alteridad y subalternidad de los campesinos indígenas. Karasik analiza cómo el reciente proceso de revitalización étnica en Jujuy ha reconfigurado estos parámetros, transformando antiguas marcas corporales de estigmatización en marcas de orgullo étnico "kolla". La autora, no obstante, también advierte sobre las paradojas de estos nuevos posicionamientos, que pueden reproducir imágenes exotizadas de una "andinidad" crecientemente mercantilizada para el consumo del turismo nacional e internacional.

Finalmente, el capítulo a cargo de Ana María Gorosito Kramer, se centra en un caso concreto del debate en torno a la pre-existencia de pueblos originarios en algunas partes del país, y si su presencia es posterior a la formación del Estado-Nación. El artículo estudia cómo los grupos mbyá-guaraní de la provincia de Misiones han sido 
HORACIO MIGUEL HERNÁN ZAPATA - Nuevos estudios sobre las luchas indígenas...

representados y estigmatizados en diversas fuentes históricas y etnográficas, y de qué manera el uso e imposición de ciertos etnónimos sobre ellos ha tenido implicancias políticas. La autora analiza cómo debates sobre el carácter "nómade" o "cazador-recolector" de los mbyá, sobre si descienden de grupos que no fueron reducidos en las misiones jesuíticas o si son originarios del Paraguay, han sido utilizados desde sectores de poder para excluirlos de sus derechos territoriales y patrimoniales. También considera cómo el actual uso de los términos "mbyá" o "guaraní", si bien intenta dar cuenta de la especificidad cultural de este grupo, también engloba a grupos guaraníes de la provincia que se autodenominan de distintas maneras.

De esta manera, Movilizaciones indígenas e identidades en disputa en la Argentina se presenta como un producto original que no sólo aporta elementos para comprender mejor la multiplicidad de experiencias, ángulos y perspectivas de las comunidades indígenas en el país tras la desarticulación de sus formas de vida autónoma. También -y más que nada- plantea nuevas miradas sobre las estrategias y prácticas políticas puestas en juego por estas poblaciones al reivindicar siempre y en todo momento -a pesar de las condiciones tan adversas y dispares en que viven- sus identidades, memorias, luchas y demandas en la escena nacional.

\section{Bibliografía}

GORDILlO, Gastón; HIRSCH, Silvia (Orgs.). Movilizaciones indígenas e identidades en disputa en la Argentina. Buenos Aires: La Crujía Ediciones, 2010. 288 p. 